\title{
Helminth Associated Infections Among Residents of
} \section{Karachi}

Aly Khan ${ }^{1, *}$, Nasira Khatoon ${ }^{2}$, Syed Shahid Shaukat ${ }^{3}$, Samina Waheed², Adnan Khan, Rozmeen Nil2

${ }^{1}$ Crop Diseases Research Institute, Pakistan Agricultural Research Council, University of Karachi, Karachi-75270, Pakistan. 2Department of Zoology, University of Karachi, Karachi-75270, Pakistan.

3 Institute of Environmental Studies, University of Karachi, Karachi-75270, Pakistan.

${ }^{4}$ Department of Microbiology, University of Karachi, Karachi-75270, Pakistan.

\section{ABSTRACT}

Background: Helminth parasite affects approximately 2 million individuals yearly throughout the world. These infections are extremely important while often receive inadequate consideration. Helminths are among the gastrointestinal parasites mainly involved in an increased ratio of inflammatory bowel disease, especially in underdeveloped and developed countries.

Objectives: To study the prevalence of helminth eggs in stool samples collected from five hospitals of Gulistan-e-Johar area of Karachi, Pakistan, among different age groups of male and female patients with the targeted age groups $<1-14,15-40$ and $>40 \mathrm{yrs}$.

Methodology: All the samples included in the study were collected according to ethical review board policy of the participating hospital. Stool samples were obtained from a total of 1042 patients, of which 198 samples were found to be positive for helminth eggs. The helminths included were Ascaris lumbricoides, Ancylostoma duodenales and Hymenolepis nana.

Results: The association between helminth infection (A. lumbricoides, A. duodenale and $H$. nana) and age group was found to be significant. Results are based on the chi-square test. Samples from males showed a noticeable prevalence of helminths than females samples. Single, double and triple infections were also recorded.

Conclusion: Present study could be very beneficial for developing programs not only for awareness in the urban and rural populations, but also for the control of infections due to helminths in Pakistan.

\section{Keywords}

Helminth infection, A. lumbricoides, $A$.

duodenale, H. nana.
*Address of Correspondence aly.khan@hotmail.com
Article info.

Received: September 25, 2020

Accepted: December 23, 2020

Cite this article Khan A, Khatoon N, Shaukat SS, Waheed S, Khan A, Nil R. Helminth Associated

Infections Among Residents of Karachi. RADS J Biol Res Appl Sci. 2020; 11(2):96-101.

This is an Open Access article distributed under the terms of the Creative Commons Attribution License (http://creativecommons.org/licenses/by/4.0), which permits unrestricted use, distribution, and reproduction in any medium provided the original work is properly cited.

\section{INTRODUCTION}

The helminth parasites affect more or less two million people worldwide every year1. So far, 342 species of helminths are associated with humans, amongst those 197 are the inhabitant of the human gastrointestinal tract2. A high rate of infection with helminth parasites may lead to severe anemia, malnutrition and loss of productivity in the workplace. It was reported that almost 819 million people are infected with Ascaris, 464 million with Trichuris and 438 million with Hookworms (Ancylostoma and Necator) amongst the rural population of the world especially, where sanitation facilities are improper ${ }^{3}$. In random samples of 1313 children aged 1 month to 12 years in villages, in nine rural districts of Southern Laos Peoples Democratic Republic was enrolled and examined for helminths prevalence using duplicate Kato-Katz thick smears. They recorded considerable morbidity among the surveyed 
children which included hepatomegaly (13.7\%), abdominal pain (13.2\%), and anemia (60.4\%) with significant signs of low body mass index and stunting. The most common worms were Hookworms and Opisthorchis viverrinit. This study summarized the clinical aspects, biology, diagnosis, treatment and epidemiology for the common and rarer human intestinal Cestodes ${ }^{5}$. The immunology of infections with helminths was also reported 6 .

Increased prevalence of intestinal helminths infection during pregnancy in the Sub-Saharan African community was reported In this survey 105 pregnant women were recruited and found positive as compared to the same number of non-pregnant ${ }^{7}$.

In another study, intestinal helminth parasites with respect to nutritional status of children aged 6-14 yrs attending school in Waskiso District, Central Uganda was noted and found that the prevalence of stunting was $22.5 \%$, underweight $5.3 \%$ and moderate acute malnutrition $18.5 \%$, respectively. The prevalence of parasites namely Trichuris trichiura was $10.9 \%$, Schistosoma mansoni was $1.9 \%$ and Ascaris lumbricoides was $0.2 \%{ }^{8}$. It was reported that in studies conducted in Pakistan, the focus was mostly on school children, low-income group and rural populations ${ }^{9}$.

In southern Malawi, the urban/rural difference along with risk factors for intestinal helminth infection was studied. Surprisingly, the overall prevalence of helminth infection was higher in urban as compared to rural subjects ${ }^{10}$.

Relations of helminths with human allergy was studied and suggested that they are of significant importance to epidemiologist as well as immunologists ${ }^{11}$. The relationship between the frequency distribution of $A$. lumbricoides and intensity of infection in human communities was reported. The factors responsible for this relationship in the human population required further study but may involve some combinations of (i) density-dependent reduction in worm number within individuals, (ii) density-dependent parasiteinduced host motility or (iii) self-treatment by heavily infected host ${ }^{12}$.

The prevalence of Taenia saginata and Hymenolepis nana infection amongst farmers, education concerned people, and shepherds of Swat were studied and found shepherds to be more prone to infection as compared to other groups $^{13}$. The incidence of intestinal parasitic infections for in- and outpatient visiting King Fahd Medical City, Riyadh,
S. Arabia for a period of five years was reported. T. trichiura and $H$. nana were prevalent and further suggested that updating the epidemiological survey of parasites at regular intervals using statistical methods ${ }^{14}$.

Work on treatment and diagnosis of intestinal helminths including Hymenolepis, Taenia, Diphyllobothrium latum and Dipylidium caninum was carried out. Niclosamide and Praziquantel are the drugs for choice for tapeworm infections ${ }^{15}$. Studies on the intestinal helminths risk factors for developing active tuberculosis in patients were made ${ }^{16}$. The most prevalent helminths in humans were A. lumbricoides, $T$. trichiura and hookworms, and there are now approximately one billion infections with each of these worldwide ${ }^{17}$.

Since, the economic burden of helminths in humans along with their co-endemicity with Acquired Immunodeficiency Syndrome (AIDS) and malaria ${ }^{18}$, is also very obvious in many of the study groups, therefore, it is important to launch awareness for controlling human helminth infection in Karachi. The drugs currently being used as anti-helminth are albendazole, praziquantel, oxamniquine and ivermectin along with the drugs developed in the early twentieth century i.e. diethylcarbamazine and mebendazole, which are the only compound medicines being used around the world.

Moreover, scarcity of available anti-helminth drugs reflects the deprecating commercial markets for human helminth infections and shows how little we know about the metabolism and mechanisms of helminths by which these parasites avoid human defense against them.

As far as the soil-transmitted helminths are concerned, WHO has suggested the use of both prevalence and intensity of infection to explain communities into transmission categories ${ }^{19}$. The present study was carried out in age groups <1-14 yrs, 15-40 yrs and $>40 \mathrm{yrs}$, to study the prevalence in male and female patients of different age groups, and whether there was single, double or triple helminth ova in various age groups of Ascaris lumbricoides ${ }^{20}$ Ancylostoma duodenale ${ }^{21}$ and Hymenolepis nana ${ }^{22,23}$ among individuals visiting five different hospitals in Gulistan-e-Johar area of Karachi, Pakistan. 


\section{MATERIAL AND METHODS}

From Oct 2018 to Sep 2019, 198 samples were found to be positive from 1042 examined with helminths namely Ascaris lumbricoides, Ancylostoma duodenale and Hymenolepis nana eggs in stool samples collected from AlShifa Medical Hospital, Family Care and Children Health Hospital, Darul-Sehat Hospital, Batool General Hospital and Darul Shifa Hospital, Gulistan-e-Johar, Karachi. The subject belonged to all age groups visiting these hospitals. The age groups were grouped $<1-14,15-40$ and $>40 \mathrm{yrs}$. The samples were collected in a sterile stool collection container carrying an identification number and a disposable wooden spatula. All samples were transported to the Parasitology Laboratory, Department of Zoology, University of Karachi where samples were immediately examined by direct smear technique for helminth eggs ${ }^{24}$. Eggs were photographed using (Optiphot-2) photomicrographic camera. For quality control, all the slides were double read by an exchange between the parasitologists. For each data set chi-square $\left(X^{2}\right)$ contingency table was analyzed to test the association of age groups and helminth infection.

\section{RESULTS}

The three types of helminth eggs recorded in the present study were $A$. lumbricoides, $A$. duodenale and $H$. nana (Fig.1a-c).
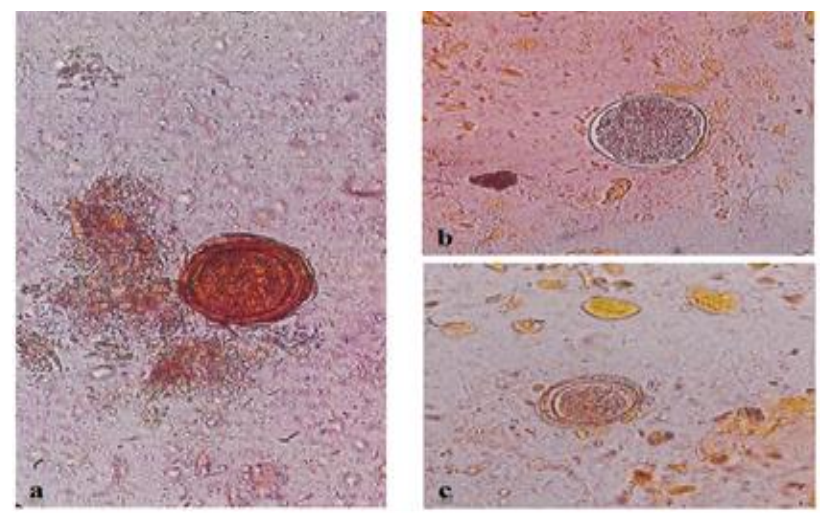

Fig. 1a-c. Eggs of a, Ascaris lumbricoides; b, Ancylostoma duodenale and c, Hymenolepis nana isolated from stool samples.

The chi-square between age groups and infection with three types of helminths eggs was found to be significant $\left(X^{2}=28.038\right.$, with $\left.d f=4, p<0.001\right)$ (Table. 1). A. lumbricoides and $A$. duodenale were most frequent in age group $<1-14$ yrs, whereas $H$. nana prevalence was equally found in age groups < 1-14 yrs and 15-40 yrs. The chi-square between age groups in male/female individuals with helminth infection was found highly significant $\left(X^{2}=\right.$ 81.332, df $=10, p<0.001$ ) (Table. 2). Male patients had more prevalence of helminths eggs in stool as compared to females.

The association tested by chi-square between age groups having single, double and triple infection with helminths was found to be significant $\left(X^{2}=58.205, \mathrm{df}=4, p<0.001\right)$ (Table. 3). In the age group, $0-14$ yrs single infection was most common, while in the age group 15-40 yrs and $>40$ yrs triple infection was most prevalent.

Table 1. Infection of Three Different Helminths in Various Age Groups. (Total Tested Samples; N=1042)

\begin{tabular}{cccc}
\hline \multirow{2}{*}{$\begin{array}{c}\text { Age } \\
\text { (Years) }\end{array}$} & \multicolumn{3}{c}{ Helminth Species } \\
\cline { 2 - 4 } & Ascaris lumbricoides & Ancylostoma duodenale & Hymenolepis nana \\
\hline$<1-14$ & 30 & 10 & 0 \\
$15-40$ & 46 & 6 & 12 \\
$>40$ & 24 & 24 & 4 \\
\hline$(p<0.001)$ chi-sq $=X^{2}=28.038 \mathrm{df}=4$ & & \\
\hline
\end{tabular}


Table 2. Infection in Male and Female Individuals Showing Positive Helminth Infection. (Total Tested Samples; $\mathrm{N}=1042$ )

\begin{tabular}{|c|c|c|c|c|c|c|}
\hline \multirow{2}{*}{ Age } & \multicolumn{2}{|c|}{ Positive } & \multicolumn{2}{|c|}{ Positive } & \multicolumn{2}{|c|}{ Positive } \\
\hline & Male & Female & Male & Female & Male & Female \\
\hline$<1-14$ & 32 & 16 & 24 & 0 & 0 & 0 \\
\hline $15-40$ & 36 & 10 & 4 & 2 & 10 & 2 \\
\hline$>40$ & 24 & 24 & 16 & 32 & 8 & 8 \\
\hline$(p<0.001)$ & 81.33 & & & & & \\
\hline
\end{tabular}

Table 3. Number of Individuals with Single, Double and Triple Helminth in Various Age Groups. (Total Tested Samples; $N=1042$ )

\begin{tabular}{ccccc}
\hline Age & Total individuals positive & Single infection & Double infection & Triple infection \\
\hline$<1-14$ & 64 & 32 & 16 & 16 \\
$15-40$ & 64 & 4 & 6 & 54 \\
$>40$ & 60 & 20 & 0 & 40 \\
\hline$(p<0.001)$ chi-sq $=x^{2}=58.205 \mathrm{df}=4$ & & & \\
\hline
\end{tabular}

\section{DISCUSSION}

Soil-transmitted human helminth infections occur in large parts of the world, including Pakistan. In the urban areas due to inappropriate sanitation, bad water quality and frequent use of open defecation locations in slum areas, there is no proper community education to prevent and control helminth infection ${ }^{9,25-29}$.

Actual prevalence must have been higher than what was obtained in this study, because the majority of the urban population takes medicines prior to stool test simply because of diarrhea. At the same time, since only a single stool sample was collected, the actual number of parasites or their eggs/ova may vary from time-to-time and day-today. It was reported that collecting a single sample may not show the actual population of helminths ${ }^{30,31}$, while three consequent samples are always considered more appropriate. It was stated that approximately one billion people are currently infected with the directly transmitted nematodes; $A$. lumbricoides and $A$. duodenale ${ }^{32}$. H. nana infection have been found to be more common as compared to A. lumbricoides in Konkor, Gadap District East, Karachi3 ${ }^{33}$. H. nana was recorded $1.3 \%$ in medical students of Multan ${ }^{31}$, whereas approximately $0.95 \%$
$H$. nana and $15.4 \%$ A. lumbricoides were reported in a study conducted in Sargodha ${ }^{34}$. H. nana was found to be more common compared to $A$. lumbricoides, but did record A. duodenale in Islamabad and Rawalpindi areas ${ }^{35}$. In another study, A. lumbricoides (11.5\%), A. duodenale $(4.95 \%)$ and $H$. nana $(4.18 \%)$ were found in samples from food handlers ${ }^{30}$. In Muzaffarabad District, $A$. lumbricoides (3.8\%) and $H$. nana (1.7\%) were found in tested samples, but $A$. duodenale was not reported 9 . A vast majority of infections are asymptomatic pathological manifestations and depend on metabolism, size, the activity of the worm. The most obvious forms of direct damage is blockage of internal organs or from the effects of pressure caused by growing parasites, thus, the mucosa of intestine reflects chemical and physical damage of tissue ${ }^{36}$. It was found that $H$. nana and Enterobius remained relatively common parasites of humans in many parts of Iran. It was reported that Hymenolepis nana was found (19\%) in children aged 2 to 15 years who were referred to the main pediatric health center of Lorestan province, Iran ${ }^{37}$.

The changes occurring in climate plays an important role in determining the future viability of human helminth parasites $^{38}$. Similarly, the time distribution pattern of disease may alter as a result of changing lifestyle of the 
people of a particular region 39 . The most common drugs being prescribed by medical practitioners in these five medical centers were mebendazole and albendazole.

Determination of occurrence and intensity of human helminth infection is an important tool / method for selective use of preventive cytotoxic drugs and to develop comprehensive programs both in rural as well as urban population along with mass awareness programs and must be launched for the helminth control.

\section{CONCLUSIONS}

The direct damage of helminths is from the blockage of internal organs or the pressure caused by growing parasites. Contaminated food must be avoided, hands must be thoroughly washed before eating, after using the bathroom and in a direct contact with animals, faeces and pre-school aged children. Avoid eating improper washed salads and usage of water that may be contaminated with sewage, faeces or wastewater runoff near storm drains.

\section{CONFLICTS OF INTEREST}

None.

\section{FUNDING SOURCE}

None.

\section{ACKNOWLEDGMENTS}

None.

\section{LIST OF ABBREVIATIONS}

A. lumbricoides Ascaris lumbricoides

A. duodenale Ancylostoma duodenale

H. nana Hymenolepis nana

Yrs Years

\section{REFERENCES}

1. Brindley PJ, Mitreva M, Ghedin E, Lustigman S. Helminth Genomics: The implications of human health. PLoS Negl Trop Dis. 2009; 3:e538. DOI: 10.1371/journal.pntd.0000538.

2. Horton JMS. Human gastrointestinal helminth infection: Are they now neglected diseases? Trends Parasitol. 2003; 19:527-31.
3. Hedley L, Wani RLS. Helminth infections: Diagnosis and treatment. Pharm J. 2015; 295:1-13.

4. Sayasone S, Utzinger J, Akkhavong K, Odermatt P. Multiparasitism and intensity of helminth infections in relation to symptoms and nutritional status among children: A cross-sectional study in Southern Lao Peoples Democratic Republic. Acta Tropica. 2015; 141:322-31

5. Craig PA, Ito A. Intestinal cestodes. Curr Opin Infect Dis. 2007; 20:524-32.

6. Allen JE, Maizels RM. Immunology of human helminth infection. Int Arch Allergy Immunol. 1996; 109:3-10.

7. Adegnika AA, Agnandji ST, Chai SK, Ramharter M, Breitling $L$, Kendjo $E$, et al. Increased prevalence of intestinal helminth infection during pregnancy in a SubSaharan African community. Wien Klin Wochenschr. 2007; 119:712-6.

8. Lwanga F, Barbara EK, Christopher GO. Intestinal helminth infection and nutritional status of children attending primary schools in Waskiso District, Central Uganda. Int J Environ Res Public Health. 2012; 9:2910-21.

9. Chaudhry ZH, Afzal M, Malik MA. Epidemiological factors affecting prevalence of intestinal parasites in children of Muzaffarabad District. Pakistan J Zool. 2004; 36:267-71.

10. Phiri K, Whitty CJ, Graham SM, Sembatya-Lule G. Urban/rural differences in prevalence and risk factors for intestinal helminth infection in southern Malawi. Ann Trop Med Parasitol. 2000; 94:381-7.

11. Cooper PJ. Intestinal worm and human allergy. Parasite Immunol. 2004; 26:455-67.

12. Guyatt HL, Bundy DA, Medley GF, Grenfell BT. The relationship between the frequency distribution of Ascaris lumbricoides and the prevalence and intensity of infection in human communities. Parasitol. 1990; 101:139-43.

13. Khan W, Noor-un-Nisa, Nawaz MA. Incidence of tapeworm infection in human population of Swat, Pakistan: An occupation based study. Pak J Zool. 2018; 50:639-45

14. Amer OSO, Al-Malki ES, Waly MI, AlAgeel A, Lubbad MY. Prevalence of intestinal parasitic infections among patients of King Fahd Medical City of Riyadh region, Saudi Arabia: A 5-year retrospective study. J Parasitol Res. 2018; 8076274. DOI: 10.1155/2018/8076274.

15. Tanowitz HB, Weiss LM, Witter M. Diagnosis and treatment of intestinal helminths. I. common intestinal cestodes. Gastroenterol. 1993; 1:265-73. 
16. Elias D, Mengistu G, Akuffo H, Britton S. Are intestinal helminths risk factors for developing active tuberculosis? Trop Med Int Health. 2006; 11:551-8.

17. Chan MS. The global burden of intestinal nematode infections - fifty years on. Parasitol Today.1997; 13:438-43.

18. Hotez PJ, Brindley PJ, Bethony JM, King CH, Pearce EJ, Jacobson J. Helminth infections: the great neglected tropical diseases. J Clin Invest. 2008; 118:1311-21.

19. Montresor A, Crompton DWT, Hall A, Bundy DAP, Savioli L. Guidelines for the evaluation of soiltransmitted helminthiasis and schistosomiasis at community level. WHO, Geneva. 1998. WHO/CTC/SIP/98.1.

20. Linnaeus $C$. Systema naturae per regna tria naturae, secundum classes, ordines, genera, species, cum characteribus, differentiis, synonymis, locis. Editio decimal, reformata. Holmiae. (Salvius). Tomus. 1758; l:1-824.

21. Dubini A. Nuovo verme intestinale umano Ancylostoma duodenale, constitutente un sesto genere dei nematoidei proprii dell'uomo. Ann Univ Med Milano.1843; 106:5-13.

22. Bilharz T. Ein Beitrag zur Helminthographia humana, au s brieflichen Mittheilungen des Dr. Bilharz in Cairo, nebst Bemerkungen von Prof. C. Th. von Siebold in Breslau. Zeitschrift für wissenschaftliche Zoologie. 1851; 4:53-76.

23. Ransom WH. An Account of the Tapeworm of the Genus Hymenolepis Parasitic in Man, Bull. No. 18, Hyg. Lab. U. S. Public Health and Marine-Hospital Service, Washington. 1901.

24. Cheesbrough M. Medical laboratory manual for tropical countries. Vol 1, $2^{\text {nd }}$ Ed. Cambridge University Press, Cambridge. 1992.

25. Bilqees FM, Khan A, Ahmad A. A survey of intestinal protozoan and helminth parasites in Karachi. Pak J Med Res.1982; 21:54-7.

26. Khan W, Noor-un-Nisa, Khan A. An investigation on incidence of intestinal parasites under and above 15 years age in farmers of Swat, Pakistan. Proc Parasitol. 2011; 52:43-53.

27. Khan W, Noor-un-Nisa, Khan A. Diversity of intestinal parasites in Male and Female students and workers of Education Department. Pak J Zool. 2015; 47:65-8.
28. Khan W, Noor-un-Nisa, Khan A. Soil transmitted helminthiasis in different occupational groups in Swat, Khyber Pakhtunkhwa, Pakistan. Pak J Pharm Sci. 2017; 30:1345-50.

29. Khan W, Noor-un-Nisa, Khan A. Prevalence and Risk factors associated with intestinal parasitic infections among food handlers of Swat, Khyber Pakhtunkhwa, Pakistan. J Food Nutr Res. 2017a; 5:331-6.

30. Rajper GM. Significant role of parasitic infestation in people concerned with food handling. Med Channel. 1999; 5:17-25.

31. Farooki MA. Intestinal parasites burden of 224 Medical students. J Pak Med Assoc.1965; 15:27-66.

32. Anderson RM. The population dynamics and control of hookworm and roundworm infections. In: Anderson, R.M. editors. Population dynamics on infectious diseases: Theory and Applications. London: Chapman and Hall. 1982; 67-109.

33. Siddiqui MI, Bilqees FM, Lliyas M, Perveen S. Prevalence of parasitic infections in a rural area of Karachi, Pakistan. J Pak Med Assoc. 2002; 52:315-20.

34. Ghauri SA, Alam M. The pattern of intestinal parasitic infestations in Sargodha area: A comparative study. Pak Pathol. 1992; 3:99-101.

35. Qureshi AH, Karamat KA, Qamer RH, Malik IA. Intestinal parasitic infestation in Rawalpindi / Islamabad area: A study of 12640 stool samples. Pak J Pathol. 1992; 3:31-9.

36. Wakelin D. Helminths: Pathogenesis and defenses. In: Baron, S. editor. Medical microbiology. $4^{\text {th }}$ edition. Galveston (TX): University of Texas Medical Branch at Galveston (Chaptor 87). 1996.

37. Mahmoudvand H, Badparva E, Khalaf AK, Niazi M, Khatami M, Nazer MR. Prevalence and associated risk factors of intestinal helminthic infections in children from Lorestan province, Western Iran. Parasite Epidemiol Control. 2020; 9:e00136. DOI:10.1016/j.parepi.2020.e00136.

38. Blum AJ, Hotez PJ. Global "worming": Climate change and its projected general impact on human helminth infections. PLoS Negl Trop Dis. 2018; 12:e0006370. DOI: 10.1371/journal.pntd.0006370.

39. Saki J, Khademvatan S, Foroutan-Rad M, Gharibzadeh M. Prevalence of intestinal parasitic infections in Haftkel County, Southwest of Iran .Int J Infect. 2017; 4:e15593. DOI: 10.5812/iji.15593. 